\title{
Finland's Low Fertility and the Desired Recovery
}

\author{
RIITTA AUVINEN
}

Research Director, Docent

The Population Research Institute

\section{Towards the good life}

After the Second World War Finland has been living in the last phase of the demographic transition. Following the exceptionally large age groups born after the war, an increasingly smaller number of children has been born annually. By the 1980 s, at the latest, people have finally started to worry in Finland about low fertility and discussed the significance this small number of children may have for Finland in the future.

When compared internationally, the economic circumstances in Finland today are good. Infant mortality is one of the lowest in the world (6.1), the average length of life has continuously increased ( 70.5 for men, 78.7 for women) and the increase is expected to continue. Family size has also decreased constantly, with average family size now at 1.6 Finland has become a society where four generations are alive at the same time and where there are small urban families, where the average standard of living is high and where it is becoming more common to live alone. Finland in the 1980 s is now completely different from what it was like one generation ago.

The total population of Finland has been increasing constantly, despite a low fertility. Therefore, not until the last few years have politicians and the general public begun to realize the significance of a low fertility for Finland's future population development. The slight increase in the population can be explained with a decreasing mortality and the accompanying increased length of life. Finland's population is aging and the population structure is changing, so that in the future there will be many old people and relatively very few children. Now still over one-half of the change in the population structure can be explained with the decrease in mortality and slightly less than one-half with the decrease in fertility. But after the year 2000 , if the population develops as predicted, over $70 \%$ of the aging of Finland's population structure will be caused by low fertility and only $30 \%$ by the increase in the length of life (Lutz, 1987).

Conclusions concerning Finland's population development were made already at the end of the $1800 \mathrm{~s}$. The first forecast estimate was published in 1934. The latest forecast is from 1986 and was published by the Social Insurance Institution. Markku Ryynänen, a researcher at this institute, had the following thoughts concerning this last-mentioned forecast.

Finland's population development in the 1900s has been imprinted by a strongly fluctuated migration, by continuously decreasing fertility, excluding the post-war exception, and by the increase in the length of life. Migration has fluctuated so vigorously that it is not conceivable that these fluctuations could have been predicted beforehand on reasonable grounds. The future development of migration is just as obscure. The changes which occur in the economic development of Sweden and Finland, for 
example, may affect the migration flow even over a short period. It is possible that the people who have emigrated (for example, in the 1970 s a total of over 130,000 persons) may return when they reach old age.

It has been hard to believe the continuous decrease in fertility. Already in the 1910 s, the decrease in fertility which had occurred was, in its own time, considered catastrophic. Now in the 1980 s the decline in fertility seems to have ceased and remained at 1.6.

At least to some extent, family policy measures can be used to influence fertility. Nevertheless, it is difficult to predict the effects of these measures. At present it seems reasonable to assume in long-range studies that fertility will stabilize at the level prevailing at the end of the 1980s.

It has also been difficult to predict the long-term development of mortality. Even now, the increase in the mortality of middle-aged men in the 1960 s can be seen as a special phenomenon. The rather strong decrease which began after this increase was also not apparent beforehand. Now, in the $1980 \mathrm{~s}$, this decrease has slowed down.

When making long-range forecasts, it has been difficult to determine the lower limit of mortality development. The development occurring in the other Nordic countries can be considered a suggestive point of comparison. Even now, their mortality is smaller than that of Finland.

Overall, population changes have stabilized now in the 1980 s, according to Ryynänen. Forecasts made even on the basis of standard assumptions today provide a rather accurate image of Finland's population development, if no unexpected changes occur. However, the old statement-still holds true that forecasts should be compiled regularly and at not very long intervals (Ryynänen, 1988).

\section{Attitudinal obstacles and practical measures}

Riitta Jallinoja, docent at the Department of Sociology of the University of Helsinki, noted in a seminar in $1988^{1}$ in her presentation »The Finnish family yesterday, today and tomorrow» that sthe conformity in the number of children in the family today is based on what we have been taught for a hundred years, that it is sensible to limit fertility. For just as long, we have also been taught that life has more to offer than taking care of children. This instruction has taken root. A mentality has been born, which has taken hold in our culture's basic structures, in our collective consciousness. This mentality has also become independent, meaning that it has become separated from the arguments which have traditionally been used to influence fertility. "A small number of children» is a value in itself, and it seems that no argument, however, well-founded, is good enough to contradict it. This value or mentality, seen as an attained right, now regulates fertility more than any other factor.

A low fertility clearly correlated earlier with a woman's level of education and employment. This correlation no longer exists. The fertility of housewives in Holland is about as low as that of wage-earning mothers in Finland. " The right of mothers to stay at home» no longer acts as a factor increasing fertility» (Jallinoja, 1988).

Thus, the individualistic thinking of an industrial society has ultimately produced a very uniform family model, whose small number of children worries society. It seems that everyone has ended up with a small family, almost as if by joint agree-

I Seminar on family policy »Does Finland want more children?», May 11, 1988, Helsinki, organized by the Finnish Population and Family Welfare Federation and the Mannerheim League for Child Welfare. 
ment. According to Jallinoja, this has occurred through a conformity in the values chosen.

Tarja Halonen, the Minister of Social Affairs, has drawn attention, however, to the daily life of families with children and to the real difficulties found therein as an explanation for low fertility. "More rooms should be found in society's values, athmosphere and culture as a whole for children and youth. It is essential that the possibilities for consumption available to families with children should be raised to the level it is for others. Child allowances should be increased manyfold. It should be possible to satisfy the demand for housing, and the quality of housing should not depend on the number of children in the family. Additional resources for child care arrangements must be provided.

More flexible possibilites and freedom of choice should be found for arranging working hours. This requires a new way of thinking, but fitting together having children and a job should be considered the starting point, instead of the either-or arrangement now prevailing.

Women, any more than men, are not about to quit their jobs and other civic duties for the sole task of taking care of children. Nothing like this is being suggested; it would be a waste of our resources. It should be possible to fit the family and employment together and, at the same time, remove the much-talked-about double labor women perform: one for their employer, one at home, worrying constantly about both and having a guilty consciousness because of not having enough time for the family» (Halonen, 1988).

Jallinoja's view, however, is contradictory to the minister's standpoint quoted above. According to Jallinoja, the aim of increasing economic resources has been to have a positive effect on fertility. "It is paradoxical that fertility has decreased as the prosperity of the people has increased. Therefore, it seems unlikely that society's measures meant to help families with children will raise fertility, although they do, of course, improve the circumstances in which these families live.

For a long time, rational grounds were presented as justification for decreasing fertility. Now rational criteria are being used to increase fertility. This is hard to take in all at once. Throughout this century we have been learning that having children is a private affair. Everyone makes their own personal decision in the matter, thus demonstrating that they are governing their own lives. This has been seen as a right which persons talking on behalf of raising fertility are threatening to violate. This is how the matter is perceived, which has even resulted in a demand that speeches in favor of raising fertility be forbidden. This is how important privacy is considered.»

And further, Jallinoja feels that »it is difficult to influence a whole mentality with individual measures, a mentality which had laid down its roots deep into our collective consciousness. The mentality itself has to change, meaning in this case that people should just want more children. Then children would be an inherent value and they in themselves would include an aspect producing pleasure. Today I can imagine only one single factor that can influence people to have two children instead of one. This factor is child day care» (Jallinoja, 1988).

Maybe the key to the argument over whether family policy can be used in Finland to affect fertility is provided by the knowledge that, in light of studies made in Finland concerning the ideal number of children in the family, there would seem to be an attitudinal readiness to have more children per family than the current 1.6. Jouko Hulkko, managing director of the Finnish Population and Family Welfare Federation Väestöliitto, has presented the societal aim as the following: »Regarding the individual, the family, kin and society, it would be good to strive for a situation 
in society where families could have the number of children they desire. The structure of the community would thus grow healthier and, over the long run, we would reach balanced population development, where generations would succeed each other, one about as large as the next» (Hulkko, 1988).

\section{The global view}

The discussion has been put in a global framework in the question presented by Jorma Sipilä, professor of social policy at the University of Tampere: »Are we still living in a world where national states are independent systems? On what basis is Finland so separated from the world that she has the right to want more children? ... Capital is a progressive force in the internationalization of the world. I believe that twenty years from now there will be more foreigners in Finland than we can now possibly imagine.

Is it the public opinion that there should be more children in Finland? I feel that there is no public opinion on this matter, as there isn't on many other matters, either. Some groups say that there shoud be more children. Others, again, are afraid of unemployment and say that youth unemployment shows that there already are too many children.

But, above all, actions suggest that the number of children is not an essential question at all... In general, all that can be said is that most permanent couples want at least one child. No broader consensus can be found» (Sipilä, 1988).

The viewpoint of public economy concerning the challenge of low fertility has been the concern for the sufficiency of social security fees during the next millennium, when the "pension bomb» explodes as the large age groups enter retirement. No simple answer has been found to this question, either. "It has been proposed that the increase in social expenditures incurred by the growing old age groups can be provided for, even if the population decreases. In the future, economic activity will not be as labor-intensive as it is now. During the past years of high unemployment, the idea may have spread that it is not worth raising children, who will then join the ranks of the unemployed. This manner of thinking is, in many respects, extremely simplistic and inaccurate» (Hjerppe, 1988).

Thus, in Finland, a distinct opinion concerning future population development has not yet been formed even in general public discussions. We are just beginning to become conscious of the situation and to discuss the effects of the possible decrease in the population. On the other hand, the factors which are apparently behind the development which has occurred are beginning to take firm shape as a basis for a possible new policy.

\section{Break-up from life style and family traditions}

Professor Kalle Österlund, chairman of the Finnish Population and Family Welfare Federation, Väestöliitto has outlined the developments of the last few decades on the basis of his long experience as a pediatrician in the following: "Finland's industrialization is still recent. Because of this, our standard of living has risen continuously and strongly. While at the end of the 1930s six out of ten Finns gained their living from agriculture, today only one in ten is dependent on agriculture. For the great majority of our population this change has meant the breakup of the former nuclear family and the disappearance of its lifestyle and family tradition. Especially 
in the care of small children, society has had to take responsibility for tasks which previously belonged to the family. This is not without its problems for both the family and society.

With the industrial structure, young people have been pulled up from their roots, from their traditional environment into a new and strange one, where one is easily left without the human contacts which abounded in the original surroundings. This has had definite effects on the life of young families with children. The previous generation is a long distance away and cannot be reached when support, advice or physical help is needed. It is difficult to create warm and close personal relationships in entirely strange surroundings.

A family can also not be founded, if there is no nest in which to do it. The housing question is in a key position, especially in the large urban centers, and not only when it is a matter of the family's first dwelling, but perhaps even more noticeably when the family grows and needs more room. In addition to the economic burden caused by children, the family must take care of seemingly endless interest payments and installments on loans and raising the family's standard of living is postponed into the far-off future. Apparently, an active search is underway in different sectors of our society for the pearl of wisdom which would provide an acceptable solution to this burning question. For the time being it has not been found, but we live in hope» (Österlund, 1988).

Thus, the factors seen as explaining Finland's population development have been both attitudinal factors, even political ones, and economic circumstances. At least in the light of historical experience, neither can definitely be left out of consideration. During this century, fertility in Finland has been exceptionally low in the decades before independence, which were the so-called years of oppression, during the depression years of the 1930s and since the 1970s, when an intense structural change began in Finland.

\section{Some conclusive remarks}

My own understanding is that both political and economic factors combined are behind the low fertility in Finland in the 1980s. The great cultural changes, which are now in question in population development, do not occur as the result of any single factor. Society can be seen as a large machine which is made up of different parts and these parts must join together reasonably well, in order for the machine to work at all. The Finnish society has, during its structural change, adopted as a basis for its organization an industrial-society machine, some parts of which still fit in poorly with the whole. The fate of the system's weakest link is to get trampled. In an industrialized society this weakest link today is the small child. A child is a burden, which people give up, and fertility remains low.

Young people.who are founding a family are already aware of the industrial-society machine's faults. They already have had experience with the way it works. Decisions which closely concern their own lives can already be based on their own experience. This experience can, in my opinion, be condensed into five points in the Finnish society in the same way as Lesthaege and Surkyn in their article concerning several other Western European countries (Lesthaeghe and Surkyn, 1988).

1) Already early in their lives, cohorts develop meaning-giving universes, which they retain throughout their adulthood. The ideas Jallinoja presented above are a good example from Finland in this respect. Value changes in any direction are always difficult. 
2) The differentiation of cultural models concerning family relationships, the disappearance of certain definite models, directs behavior according to economic stimuli. Behavior is then determined by, among other things, the possibilities for consumption available to families with children, as Minister Halonen sees the situation. Monetary gains and losses become contributory factors of fertility, and family policy can only be used to affect fertility over a short term. Finland's family policy of the 1970 s is a good example of this.

3) The answers provided by social institutions affect childbearing behavior and the timing of children. In Finland, the still badly deficient institutional answer to the needs of families with children - who are supposed to bear more children is child day care. With the family's first child, enough experience is gained of »daycare misery» and the insecurity caused by the situation. A second child, not to speak of a third, is never born.

4) Founding a family depends on the atmosphere prevailing in society and one factor with a negative effect on this atmosphere is very-far-advanced individualism. The number of children per family is lowest in the Helsinki metropolitan area and childlessness is most common among Helsinki women. Long years of schooling delay family formation until people are much older, so that they are already accustomed to being strongly independent, even accustomed to a personal hedonism from which it is difficult to retreat when having a child. Having children becomes too demanding and costly mentally.

5) The privatization of society will apparently continue in the future. This can be seen as a counterforce to a nationalization and social control, even to a »blanket nationalization", which have been carried too far. What privatization will be allowed to be in the society of the future will probably also determine the population development of the future. For this development, taxation will most likely have a greater significance than traditional family policy.

The possibilities for real individualism and self-determination will become key questions in finding the motivation to act for the best of society. Motivation, no less than the right to self-determination, will not be realized, if the young educated age groups, as soon as they enter the labor market, when they are setting out in their lives and forming a family, have to pay a marginal tax of over 50 percent, as now already happens in Finland. Because of youth and education, the pay level will be forced to a high level compared to that of the older, less-educated age groups. However, the older age groups already have the capital they have acquired throughout their lifetime as security, which young people are often totally lacking. High taxation at the poor beginning the of adult life is then seen as punishment for ability and gaining an education. In addition, the tax is focused on a time when student loans must be paid back, when housing must be saved for and when child day care has to be paid for. At this time, an additional child may be the straw that breaks the camel's back.

I consider it possible that, in Finland, fertility will remain low until past the 1980 s, partly due to a lack of political solutions. The absolute decreasing of the population, which is predicted to occur at the end of the 1990s, may, nevertheless, be a turning point for the general public and thus also for politicians, which will lead to changes in opinion and to real solutions for society. However, in regard to our future population structure, it is unfortunate that a belated changeover may lead to a heavy supporting relationship, when an increasing number of old people should be taken care of and the number of annual births should increase markedly at the same time, in order that we can, on the whole, preserve the aim of zero-population growth.

The number of children that people are going to have is naturally the citizens' 
own private affair. Reproduction can be influenced only indirectly in a democratic society. A society must be created in which a child will fit. Parents must be allowed the opportunity to live a modern everyday life of good quality. This calls for new and original contributions to social renewal. A new culture must be created, where the central factor is not the system's demands or narrow terms on which it functions, but a versatile daily life which understands different concepts about people and choices based on different sets of values. Maybe this is not just a utopian view even in an industrial society.

\section{References}

Halonen, Tarja (1988) Kaikkien lasten päivähoito olisi saatava kuntoon vuoteen 1995 mennessä (Day care to all children by 1995). Talk given on May 11, 1988. Unpublished.

Hjerppe, Reino (1988) Ennustepohjaisen väestönkehityksen seuraukset yhteiskunnassa (The consequences of a projected population development in society from the viewpoint of public economy). Talk given on May 11, 1988. Unpublished.

Hulkko, Jouko (1988) Uusi yhteiskunta - uusjako perhepolitiikkaan (New society - new family policy). Talk given on May 11, 1988.

Jallinoja, Riitta (1988) Suomalainen perhe eilen, tänään, huomenna (Finnish family yesterday, today, tomorrow). Talk given on May 11, 1988. Unpublished.

Lesthaeghe, R. and Surkyn, J. (1988) Cultural dynamics and economic theories of fertility change. Population and Development Review 14(1): 1-45.

Lutz, Wolfgang (1987) Effects of fertility trends on population aging in Finland. Yearbook of Population Research in Finland 25: 19-29.

Ryynänen, Markku (1988) 50 vuotta väestöennusteita (Fifty years of population projections in Finland) Sosiaalivakuutus 26(4): 117-121.

Österlund, Kalle (1988) Perheen pienenemisen yhteiskunnalliset ja yksilöliset seuraukset (The societal and individual consequenses of the decrease in family size). Talk given on May 11, 1988. Unpublished. 